\title{
A importância dos localizadores apicais para o sucesso do tratamento endodôntico
}

\section{The importance of apical locators for the success of endodontic treatment}

Bolam M, Costa FLM, Barasuol JC, Felippe GS, Felippe MCS, Felippe WT. Estudo comparativo de três localizadores apicais eletrônicos na determinação do comprimento de trabalho. Dental Press Endod, 2018 May-Aug;8(2):42-6.

Ana Paula Fernandes Ribeiro ${ }^{1}$ ${ }^{1}$ Graduanda do Curso de Odontologia - Faculdade de Odontologia de Lins - Universidade Metodista de Piracicaba

Determinar o comprimento apropriado de trabalho é um dos passos fundamentais para se obter o sucesso no tratamento endodôntico. Para isso, é necessário localizar adequadamente o forame apical. Devido a variáveis anatômicas, nem sempre esse forame coincide com o ápice anatômico, podendo, em alguns casos, localizar-se lateralmente. ${ }^{1}$ Alguns profissionais lançam mão do método radiográfico para obter a mensuração do canal, entretanto, utilizar apenas essa técnica não garante exatidão na definição do comprimento ideal de trabalho, pois o exame radiográfico é ancorado em uma imagem bidimensional de um objeto em três dimensões. Os localizadores apicais, então, surgiram para garantir uma melhor precisão da técnica.

Existem diversas gerações e marcas desses aparelhos e sua eficácia já é comprovada. Dentre as tantas opções existentes no mercado, o cirurgião-dentista deve optar pelos equipamentos que proporcionam maior acurácia no momento de mensurar a constrição apical. Bolam et al., 2018 realizaram um estudo in vitro, onde avaliaram três diferentes localizadores apicais. Para isso selecionaram 100 dentes humanos extraídos e sua amostra final foi composta por 95 dentes unirradiculares e com rizogênese completa. Os dentes foram devidamente limpos e numerados e o acesso endodôntico foi realizado. A patência foi feita com lima K \#15 e para a mensuração utilizouse a técnica direta e a eletrônica. Os aparelhos eletrônicos avaliados foram: Neosono Ultima EZ (Amadent, EUA), Foramatron IV (Parkell, EUA) e Tri Auto ZX (J. Morita Corp., Japão).

A comparação entre os métodos direto (comprimento do dente - CD) e eletrônico, localizando o forame apical, revelou que o aparelho Neosono Ultima EZ forneceu 74 medidas aceitáveis, ou seja, 74 medidas coincidentes com o comprimento do dente ou diferentes $\pm 0,5 \mathrm{~mm}, \mathrm{e} 21$ medidas consideradas inaceitáveis (uma além do forame apical e 20 aquém). O Foramatron IV obteve 59 medidas aceitáveis e 36 inaceitáveis (duas além do forame e 34 aquém). O Tri Auto ZX conferiu 82 medidas aceitáveis e 13 inaceitáveis (duas além e 11 aquém do forame apical).

A comparação entre os comprimentos obtidos pelos métodos direto (CD) e eletrônico, localizando a constrição apical, revelou que o Neosono Ultima EZ forneceu 50 medidas aceitáveis e todas as 45 medidas consideradas inaceitáveis ficaram aquém do forame. Utilizando-se o Foramatron IV, 73 medidas foram consideradas aceitáveis, onde apenas foram 22 inaceitáveis (quatro ficaram além do forame e 18 aquém). O Tri Auto ZX forneceu 80 medidas aceitáveis e15 medidas inaceitáveis (13 além e duas aquém do forame apical). 
A precisão dos localizadores apicais na determinação do comprimento dos dentes mostra o quão importante é a sua utilização no tratamento endodôntico. Dos aparelhos estudados no presente trabalho, todos apresentaram uma boa margem de acerto e quando a aferição foi inadequada, na maioria das vezes, não ultrapassaram o forame apical, dessa forma não causaria sobreinstrumentação e injúrias aos tecidos do periápice. Os localizadores apicais são dispositivos muito úteis, que permitem respeitar os princípios biológicos em endodontia e, portanto, uma melhor recuperação após tratamento. ${ }^{1} \mathrm{O}$ cirurgião-dentista deveria associar as duas técnicas (direta e eletrônica) no momento da mensuração do canal, para proporcionar ao paciente um tratamento com maior garantia de sucesso.

\section{REFERÊNCIA}

1- Andrade-Rojas BM, Guillen-Guillen RE. Localizadores apicales: análisis comparativo de la precisión de la longitud de trabajo entre el localizador apical IROOT (META BIOMED) y el ROOT ZX II (MORITA). Dom. Cien. 2017 mayo;3(2):841-862. https://dialnet.unirioja.es/ servlet/articulo?codigo $=6325891$ 